\title{
Pensamento Estratégico nas Organizações
}

\author{
Strategic Thoughts in Organizations
}

Juliane Ines Di Francesco Kich

Doutoranda em Administração. Universidade Federal de Santa Catarina. Florianópolis, SC. Brasil. E-mail: julikich@gmail.com

\section{Maurício Fernandes Pereira}

Professor do Programa de Pós-graduação em Administração. Departamento de Ciências da Administração da UFSC. Universidade Federal de Santa Catarina. Florianópolis, SC. Brasil.E-mail: mfpcris@gmail.com

\section{Resumo}

Este trabalho busca analisar uma nova forma de pensar as estratégias organizacionais, através de uma discussão teórica sobre o termo "pensamento estratégico", e o seu desenvolvimento nas organizações. Para isso, realizou-se uma pesquisa bibliográfica, com o intento de aprofundar o tema e alcançar um embasamento conceitual, o qual pode subsidiar análises posteriores. Dentre os resultados da pesquisa, destacase que as características pragmáticas do planejamento estratégico parecem não ter mais espaço no atual mundo organizacional, esta ferramenta precisa estar interligada ao processo de pensamento estratégico para trazer resultados mais efetivos. Nesse sentido, o desafio se apresenta em como as organizações podem desenvolver um planejamento estratégico que incentive o pensamento estratégico ao invés de minálo, assim como o desenvolvimento de ferramentas que fomentem a capacidade de pensar estrategicamente em funcionários de todos os níveis hierárquicos.

Palavras-chave: Estratégia. Planejamento. Pensamento.

\begin{abstract}
This paper aims to analyze a new way of thinking about the organizational strategies through a theoretical discussion of the term "strategic thoughts", and its development in organizations. To achieve this, a bibliographical research was conducted in order to go more deeply on the theme and reach a conceptual background, which can support further analysis. Among the results of this research, it is emphasized that the pragmatic characteristics of strategic planningappears to not have more space in the current organizational world, this tool needs to be interconnected to the strategic thought process to bring more effective results. In this regard, the challenged is present in how the organizations could develop a strategic planning that encourages strategic thoughts instead of undermine it, as well as, the development of tools that promote the ability to think strategically in all employees, regardless of the hierarchical levels.
\end{abstract}

Keywords: Strategy. Planning.Thoughts. 


\section{INTRODUÇÃo}

Ao longo de sua história as empresas trabalham para transformar suas organizações em organizações resolutivas. Elas delegam funções tradicionais da matriz, como planejamento e gestão de recursos humanos às unidades de negócios individuais; tentam aumentar a esfera de liberdade operacional de funcionários de todos os níveis; abandonam as operações tangenciais e concentram-se nos negócios essenciais; buscam estimular os riscos pessoais; enfatizam a responsabilidade individual; invertem a hierarquia organizacional; entre outras transformações. (HAMEL, PRAHALAD, 1995)

Com isso, observa-se que arquétipos organizacionais centralizados e burocráticos, voltados para o controle e centrados na tecnologia, das décadas de 60 e 70, não têm mais espaço na atual vida organizacional. (HAMEL, PRAHALAD, 1995)

Para lidar com essas transformações, é preciso que as organizações aprendam a lidar com o futuro de modo não linear; é necessário aprender a lidar com o pensamento complexo e sistêmico e abandonar, na maioria das situações de tomadas de decisões, o modelo linear e cartesiano de conceber e analisar as coisas. (BOSSIDY, 2005; HAMEL; PRAHALAD, 1995; MINZTBERG, 2004; SENGE, 2006)

Neste sentido, o processo da estratégia, foco deste estudo, também sofreu suas transformações com o passar dos anos. As organizações iniciaram com a utilização de estratégias ao planejar em detalhes a produção de massa em meados do século passado, através dos modelos matemáticos e lineares, por meio dos quais os empresários aprenderam a planejar o lucro, elaborar orçamentos e planos de longo prazo. $\mathrm{Na}$ década de 1970, com a crise do petróleo, observou-se a necessidade de levar em conta as chamadas variáveis ambientais e as composições de cenários alternativos para melhor planejar os negócios, momento em que ocorreu o boom do planejamento estratégico. Mais adiante, nos anos 80 , foi constatado que o posicionamento da empresa no setor e a cadeia de valor nos negócios eram relevantes para a compreensão $e$ formulação da estratégia, e com isso foram criadas as vantagens competitivas. Na década seguinte, para atender às demandas de qualidade, produtividade $e$ reengenharia de processos, a aprendizagem em grupo para construir estratégias passou a ser utilizada, $e$ as empresas passaram a ser consideradas organismos vivos. A concorrência também foi reconfigurada, uma vez que uma empresa passou não apenas a disputar espaços de mercado e clientes com outras, mas também a cooperar e se relacionar com os concorrentes. Mais recentemente, percebeu-se que as organizações lidam com uma forma de conhecimento complexa $e$ há a necessidade de novos modelos de trabalho para criar e implementar estratégias de negócio. (AMOROSO, 2002)

Deste modo, hoje se reconhece que um processo de estratégia envolve além de análise de dados, também percepção, insight, intuição, criatividade, síntese e a capacidade de interconexão de processos complexos de observação que ocorrem na mente, formando obviamente uma rede intrincada de pensamentos. (MINTZBERG, 2004)

Intimamente ligado à estratégia, o planejamento estratégico é uma ferramenta organizacional que merece destaque, uma vez que ele visa englobar toda a organização, ele se relaciona com todos os níveis hierárquicos da organização, além de se envolver com outros fatores organizacionais, influenciando e sendo influenciado por eles (ACKOFF, 1982; BOSSIDY e CHARAN, 2002; HALL, 1984; HREBINIACK, 2006; $\mathrm{KICH}$ e PEREIRA, 2011; MINTZBERG, 2003), e, dessa forma, enfrentando determinadas limitações que prejudicam o seu funcionamento, o tornando alvo de uma série de críticas.

A rigidez do processo, a lógica e a linearidade com que o planejamento estratégico é desenvolvido, algumas vezes sendo tão formal a ponto de ficar isolado e sem inter-complementariedade, sendo complexo $e$ intrincado demais em sua formação, é uma das principais críticas, que com o passar dos anos, vem se acentuando em relação a esta ferramenta (MINTZBERG, 2004). Neste sentido, que a partir da década de 1990, o paradigma no campo da estratégia mudou para a fase do pensamento estratégico. (HERACLEOUS, 1998)

O que se observa é que uma série de autores vem tratando da necessidade de desenvolver o "pensamento estratégico" nas organizações, fazendo com que todos os níveis da organização pensem estrategicamente, para além da formalização de um planejamento estratégico.

Contudo, com base nessas questões que este artigo artigo busca analisar uma nova forma de pensar as 
estratégias organizacionais, através de uma discussão teórica sobre o termo "pensamento estratégico" e o seu desenvolvimento nas organizações.

Através do estudo das críticas endereçadas ao processo da estratégia e as limitações que ela enfrenta na "vida real" das organizações, denota-se a necessidade de novos estudos na área que auxiliem as organizações a desenvolverem $e$ implantarem suas estratégias em tempo hábil.

A discussão téorica sobre "pensamento estratégico" se faz pertinente uma vez que, segundo Bonn (2001), Goldman (2012) e Tavakoli e Lawton (2005), ainda falta uma compreensão e unidade teórica sobre o termo; também devido à atualidade do tema, e visto que, de acordo com Lietdtka (1998), as implicações das visões sobre pensamento estratégico desafiam toda a academia e praticantes a repensarem a capacidade de tomada de decisão estratégica e dos processos tradicionais de planejamento.

Nessa orientação, o presente artigo apresenta, além desta introdução, a seguinte estrutura: a descrição da metodologia utilizada para seu desenvolvimento; uma seção que busca esclarecer o termo "pensamento estratégico", no intuito de buscar a compreensão do que ele representa; uma segunda seção que apresenta a distinção entre pensamento estratégico e planejamento estratégico, assim como o caráter de complementariedade destes dois processos; uma terceira seção identificando os modelos para o desenvolvimento do pensamento estratégico nas organizações, já desenvolvido por uma série de autores renomados na área e, por fim, as conclusões e referências.

\section{Metodologia}

A presente pesquisa foi realizada por meio de uma pesquisa bibliográfica, descritiva e qualitativa, que utilizou o método de levantamento de fontes secundárias, como livros e artigos disponíveis sobre o tema em questão.

Segundo Gil (1994), a pesquisa bibliográfica desenvolve-se a partir de material já elaborado, sobretudo aquele já consolidado em livros e artigos científicos, em relação aos temas estudados. Ela se justifica pela oportunidade de análise que oferece sobre um determinado tema, sob um novo ponto de vista, o que permite que se chegue a novas conclusões, uma vez que a bibliografia existente oferece meios não somente para resolver problemas conhecidos, mas também para explorar novas áreas, onde questões ainda não foram suficientemente cristalizadas. (LAKATOS; MARCONI, 2002)

Diante disso, a pesquisa bibliográfica torna-se especialmente válida para a realização deste trabalho, que busca analisar uma nova forma de pensar as estratégias dentro das organizações, através do pensamento estratégico. O estudo bibliográfico se apresenta como um meio para apreender sobre o conceito "pensamento estratégico", ainda não completamente claro na literatura científica, e seu desenvolvimento nas organizações.

\section{Pensamento Estratégico: Compreensão Do Termo}

Durante décadas as empresas utilizaram intensivamente o planejamento estratégico, e com essa demanda a ferramenta acabou se tornando sinônimo de estratégia, e apresentando uma série de falhas ao longo dos seus anos de uso, como já citado na introdução deste trabalho.

No entanto, a partir da década de 1990, o paradigma no campo da estratégia mudou para a fase do pensamento estratégico (HERACLEOUS, 1998). Porém, como a terminologia na área de estratégia sempre foi controversa, com diferentes escritores usando os termos de planejamento estratégico, estratégia e gestão estratégica de diferentes maneiras; com a introdução do termo "pensamento estratégico" não foi diferente, o que criou um forte debate na literatura de estratégia sobre o que realmente o constitui. (O'SHANNASSY, 1999)

Bonn (2001) e Tavakoli e Lawton (2005) afirmam que realmente não há um acordo na literatura sobre o que é pensamento estratégico, e não é claro o que ele quer dizer. Segundo Goldman (2012), há uma falta de compreensão teórica sobre "pensamento estratégico", inclusive o comparando a termos como "planejamento estratégico" e "gestão estratégica". No entanto, alguns autores estabelecem definições.

De acordo com Wilson (1994), o pensamento estratégico é assim chamado por indicar uma gama de pensamentos dedicados à estratégia, ou seja, o 
procedimento mental sobre a operacionalidade de planos a serem estruturados.

Para Lawrence (1999), em geral, pode-se argumentar que o pensamento estratégico envolve pensar $e$ agir dentro de um determinado conjunto de pressupostos e alternativas potenciais de ação, bem como desafiadoras hipóteses existentes e alternativas de ação.

Segundo Amoroso (2002, p. 45), o “[...] pensamento estratégico é uma rede de interconexões entre processos de observação e processamento da informação, que envolve percepção, razão $e$ intuição [...]", indo além da estratégia.

De acordo com Salazar (2003), o pensamento estratégico é uma base que, quanto melhor trabalhada e depurada, permitirá que o subsequente plano tenha uma sustentação adequada e condizente com a dinâmica inerente ao tempo de sua execução, além de evitar que o planejamento estratégico se torne inviável ou obsoleto por falta dessa etapa.

Belmiro (2003, p. 295) assim define o pensamento estratégico:

[...] tenta compreender a natureza das coisas, as raízes das mudanças e dos fenômenos. Ele cria a oportunidade de respostas para as circunstâncias atuais e ações nas quais o caminho criado para o futuro ultrapassa qualquer previsão que possa ter sido criada pela simples projeção do que possa ter existido no passado.

Tavakoli e Lawton (2005) afirmam que o pensamento estratégico é o processo cognitivo que pode e deve proceder as decisões estratégicas e ações. Para os autores, o pensamento estratégico ocorre quando uma pessoa contempla o futuro de uma organização, tendo em consideração as suas variáveis ambientais e de competência.

Nesse mesmo sentido, Goldman, Cahill e Filho (2009, p. 406) assim define o termo:

O pensamento estratégico é a atividade do indivíduo de pensar nos benefícios das organizações. O seu objetivo é descobrir estratégias competitivas para posicionar a organização significativamente diferente do presente. Pensar estrategicamente não é o mesmo que preparar um plano estratégico, com uso de táticas e detalhes para atingir metas e objetivos. $\mathrm{O}$ pensamento estratégico é o pensar que contribui para o amplo, para conceitos fundamentais que focalizam a direção futura de uma organização com base no ambiente, antecipando suas condições.

No entanto, para que possa ser considerado efetivo, Belmiro (2003) acredita que o pensamento estratégico precisa ser compartilhado com muitos indivíduos, no qual um caminho de ação pode ser independentemente coordenado através da organização. Para o autor, a primeira e mais importante tarefa do pensamento estratégico é disponibilizar uma teoria de incerteza e mudança constante do mundo para ser abordada, e não uma teoria em que o trabalho possa ser determinado pelo exame de certos critérios. (BELMIRO, 2003)

Do mesmo modo, Maxwell (2010) acredita que as organizações são bem-sucedidas em seus objetivos, de forma eficiente e eficaz, quando atingem o pensamento estratégico e este é enraizado em toda a organização, tornando-se assim fonte de vantagem competitiva.

Também para Goldman (2012), ao mesmo tempo em que a abertura na parte superior é reconhecida é também necessário desenvolver a capacidade de pensamento estratégico das pessoas em níveis mais profundos das organizações.

Contudo, as incertezas, citadas por Belmiro (2003) e demais autores, são inerentes a vida organizacional, uma vez que todas as pessoas têm preocupação sobre o que poderá ocorrer no futuro, principalmente se tiverem sob sua responsabilidade a administração de uma organização, seja na qualidade de proprietário ou de funcionário, precisam estabelecer diretrizes para que as atividades de hoje e de amanhã resultem em esforços proveitosos. (SALAZAR, 2003)

\section{Pensamento Estratégico Versus Planejamento Estratégico: DIFERENÇAS E COMLEMENTARIEDADE}

Diferente de falar sobre planejar, que envolve análise, metas, etapas e sua formalização, assim como a articulação das suas consequências; o pensamento estratégico é síntese, envolvendo intuição e criatividade, resultado em uma perspectiva integrada, uma visão não muito articulada de direção, que deve estar livre 
para surgir a qualquer momento e em qualquer parte da organização. (BELMIRO, 2003)

Para Heracleous (1998), Lietdka (1998), Lawrence (1999) e Mintzberg (2004), o pensamento e o planejamento estratégico são diferentes e ocorrem em diferentes estágios do processo de estratégia.

Na visão de Heracleous (1998), o pensamento estratégico e o planejamento estratégico estão interligados em um processo dialético, no qual ambos são necessários para uma gestão estratégica, sendo que cada um por si sozinho não é suficiente. Para o autor, os processos não são importantes em si mesmos, mas sim como meios de incentivo ao conjunto de mente criativa e analítica, ou seja, ser criativo e depois ver as implicações do mundo real, e ser sintético, mas também analítico.

O planejamento estratégico não pode produzir as estratégias porque ele é pragmático e formalizado, se caracteriza como um processo analítico, e por isso deve acontecer após as estratégias terem sido decididas, descobertas ou simplesmente emergidas (HERACLEOUS, 1998). A Figura 1 demonstra a visão de Heracleous (1998) no que tange as relações entre o planejamento e o pensamento estratégico:

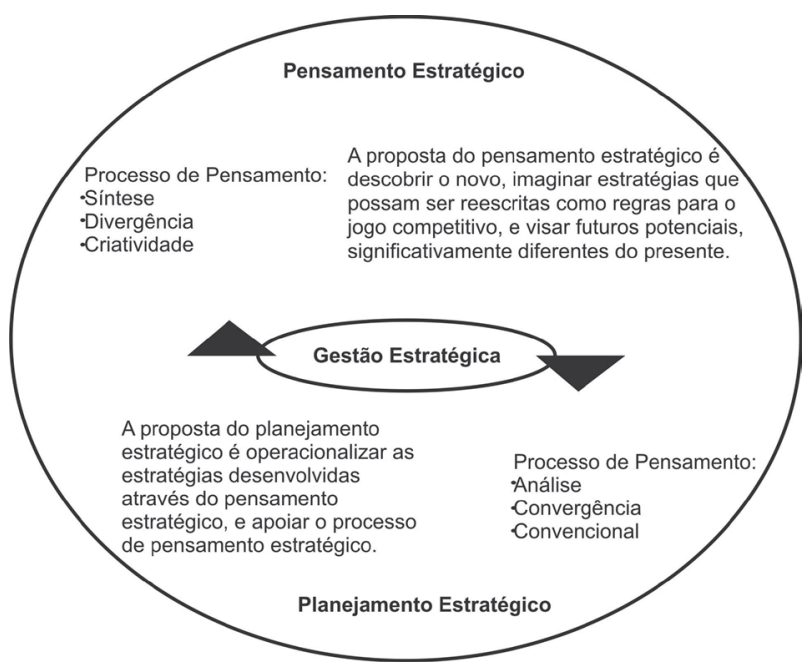

Figura 1: Pensamento Estratégico e Planejamento

Estratégico

Fonte: Adaptada de Heracleous (1998, p.485)

De acordo com a figura do autor, o processo do pensamento estratégico envolve síntese, divergência e criatividade, enquanto o processo do planejamento envolve análise, convergência e o convencional. Com isso, a proposta do pensamento estratégico é descobrir o novo, imaginar estratégias que possam ser reescritas como regras para o jogo competitivo, e visar futuros potenciais, significativamente diferentes do presente. Enquanto a proposta do planejamento estratégico consiste em operacionalizar as estratégias desenvolvidas através do pensamento estratégico, e apoiá-lo. Heracleous (1998, p.486) sintetiza sua visão na seguinte passagem: "[...] tudo se resume à capacidade de subir e descer a escada da abstração, e ser capaz de ver tanto a grande figura quanto as suas implicações operacionais, o que caracteriza líderes e estrategistas de destaque".

Esta, para Heracleous (1998), se apresenta como a melhor prática possível para a estratégia nas organizações, onde o pensamento e o planejamento estratégico ocorrem interativamente, onde há uma busca contínua de novas e criativas estratégias, que podem nascer na mente dos estrategistas ou podem surgir a partir da base da organização. Bem como, também representa o emprego de processos analíticos para determinar a viabilidade das estratégias, e planejar a sua execução.

Do mesmo modo, para Lawrence (1999), o planejamento estratégico muitas vezes leva a um acordo entre os estrategistas para decidir qual a direção que a organização deve seguir, e quais os recursos devem ser alocados para que ela caminhe na direção estabelecida; e com isso surge uma das críticas mais comuns ao planejamento estratégico, ou seja, ele está muito preocupado com a extrapolação do presente e do passado ao invés de focar em como reinventar o futuro. Enquanto, por outro lado, o pensamento estratégico refere-se a um criativo processo de pensamento, como um modo de tomada de decisão estratégica que é associado a como reinventar o futuro, a criação de um novo espaço competitivo, em oposição a lutar com crescimento lento ou encolhimento de mercados, por exemplo. Como um desvio significativo do planejamento estratégico, o pensamento estratégico questiona os parâmetros estratégicos próprios e, portanto, é análogo à aprendizagem.

Contudo, embora a literatura deixe a impressão de que essas duas abordagens da estratégia - planejamento e pensamento - sejam incompatíveis uma com a outra, Lawrence (1999) destaca que para muitos dos teóricos e praticantes da estratégia, ambos são necessários em qualquer processo de estratégia. $\mathrm{O}$ autor justifica que na medida em que pensar no futuro pode ser importante, não há dúvida de que 
os processos também precisam ser colocados em prática para permitir aos gestores atender a questões estratégicas no meio das crises do dia a dia. Portanto, não se pode simplesmente abandonar toda a atenção para o processo do planejamento estratégico; afinal, a criatividade de estratégias emergentes inovadoras, providas do pensamento estratégico, ainda precisa ser operacionalizada através do pensamento convergente $e$ analítico do planejamento estratégico. Assim, ao mesmo tempo em que o planejamento é vital, ele não pode, por si só, produzir estratégias únicas que vão desafiar as fronteiras industriais e redefinir as indústrias, a menos que estimule a criatividade, como é o caso da utilização de cenários alternativos para o futuro. (LAWRENCE, 1999)

Com isso, Lawrence (1999) quer esclarecer que o pensamento estratégico e o planejamento estratégico se adequam um ao outro, em um processo em que o planejamento incorpora, em vez de minar, o pensamento estratégico.

É nesse sentido que Langley (1988, p. 48 apud MINTZBERG, 2004, p. 268) afirma que "[...] as ideias não surgem no planejamento [...] as ideias estão no ar". Todavia, o plano forçará a fazer um esforço para agrupar as coisas e definir essas orientações com mais clareza, se constituindo em apenas uma oportunidade para os profissionais articularem suas ideias.

Do mesmo modo, Belmiro (2003) e Tavakoli e Lawton (2005) afirmam que o planejamento estratégico só pode ter lugar depois de o pensamento estratégico acontecer.

Fairholm e Card (2009) seguem essa mesma linha de raciocínio, considerando que o pensamento estratégico e o planejamento estratégico se integram e se informam mutuamente. Para os autores, a união do pensamento estratégico com o planejamento significa a união da alma com o corpo da organização. Segundo os autores, as anomalias, a inconstância do comportamento humano e as limitações que a análise desempenha são fatores significativos no resultado organizacional, e ignorá-las é arriscado, uma vez que são elas que levam a um planejamento incompleto. Nesse sentido, que o pensamento estratégico completa o planejamento, devido à sua capacidade de sintetizar, em vez de analisar, e devido ás suas funções focadas no lado mais informal da organização, que abre caminho para a inovação, flexibilidade e criatividade, as quais são tão importantes, ou mais, que os procedimentos de rotina.

\section{Pensamento Estratégico: Teorias e Modelos}

Embora sejam os indivíduos que pensem estrategicamente, e não as organizações, autores como Hamel e Prahalad (1995), Graetz (2002), Liedtka (1998) e Mintzberg (2004, 2010), afirmam que são elas - as organizações - que devem fornecer o contexto de apoio para seus membros desenvolverem tal capacidade.

Graetz (2002), embora defenda que seja possível treinar as pessoas a pensar estrategicamente, combinando criatividade e treinamento com sucesso em situações não estruturadas, sugere que o pensamento estratégico é uma habilidade mais comumente encontrada em pessoas que são criativas e capazes de trabalhar fora de seus níveis de conforto.

Para Maxwell (2010), a cultura organizacional deve apoiar os indivíduos e encorajar suas habilidades de pensamento estratégico, uma vez que apoiar o pensamento estratégico e planejamento ao longo dos níveis organizacionais mantêm a vantagem competitiva.

Contudo, a complexidade dos elementos oriundos do pensamento estratégico levou vários estudiosos a tecerem teorias, e pode-se dizer modelos, a respeito do assunto. Na sequencia, são apresentadas resumidamente as teorias e modelos de outros autores, que tratam do tema pensamento estratégico, embora alguns deles utilizem diferente nomenclatura.

\subsection{Hamel e Prahalad (1995)}

Hamel e Prahalad (1995) apresentam uma visão estratégica diferente da que prevalece em muitas empresas. Os autores defendem uma visão que reconhece que uma empresa precisa desaprender grande parte de seu passado para poder descobrir o futuro, $e$ reconhece que não é suficiente colocar a empresa em uma posição ótima dentro dos mercados existentes. Os autores defendem que o desafio é penetrar na nuvem de incerteza e desenvolver uma grande capacidade de previsão dos paradeiros dos mercados de amanhã, uma visão que reconheça a necessidade de mais do que "[...] a dança ritual da chuva do plane- 
jamento anual incrementalista". Hamel e Prahalad (1995, p. 28) afirmam:

Acreditamos que a forma como muitas empresas elaboram sua estratégia está tão desatualizada e é tão tóxica quanto sua organização. Entretanto, para enxugar e adequar uma organização, ainda é preciso cérebro do principal executivo ou do responsável pelo planejamento estratégico. Ao contrário, é uma amálgama da inteligência e imaginação coletiva dos gerentes e funcionários de toda empresa, que precisam possuir uma visão ampliada do que significa "ser estratégico".

Nesse sentido que os autores defendem o uso do que denominaram "arquitetura estratégica", a qual elabora a planta para a construção das competências necessárias para dominar os mercados futuros. $\mathrm{O}$ termo "arquitetura estratégica" procede do pressuposto de que o futuro não precisa apenas ser imaginado, precisa ser construído; assim como um arquiteto precisa ser capaz de sonhar com as coisas que ainda não foram criadas e precisa ser capaz de gerar uma planta que mostra como transformar o sonho em realidade, sendo então um sonhador e um planejador, que casa arte com engenharia industrial. (HAMEL; PRAHALAD, 1995)

Desse modo, o objetivo da arquitetura estratégica consiste em indicar as trilhas básicas na evolução de um setor ou de uma série de tecnologias, constituindo uma função chave da alta gerência, por ser um referencial útil para o gerenciamento eficaz de inovações e possibilitando a eles a identificação das atuais competências essenciais e daquelas que necessitam de desenvolvimento. (PRAHALAD; FAHEY; RANDALL, 1999)

Como ponto crucial da arquitetura estratégia, Hamel e Prahalad (1995) citam a "intenção estratégica", a qual se pode comparar ao que neste capítulo foi denominado de "pensamento estratégico", uma vez que é definida como aquela que oferece a energia emocional $e$ intelectual para a jornada apontada pela arquitetura estratégica.

A intenção estratégica consiste na expressão das aspirações das organizações, ela busca criar uma obsessão em vitória de mercado, a qual se converte em uma agenda competitiva compartilhada em toda organização, a qual necessita de uma arquitetura estratégica para oferecer um referencial que alavanque os recursos corporativos que sejam consistentes com a intenção estratégica. (PRAHALAD; FAHEY; RANDALL, 1999)
Para transformar a intenção estratégica em realidade, Hamel e Prahalad (1995) acreditam que todos os funcionários devem saber exatamente de que forma sua contribuição é essencial para a sua concretização. Não só todos na organização precisam achar o objetivo emocionalmente propulsor, como também todos os funcionários precisam entender a ligação entre seu próprio trabalho e a concretização da meta. Os autores sugerem que todo funcionário tenha uma ficha pessoal de pontuação diretamente relacionada ao seu trabalho, no sentido do desafio que está buscando em um determinado prazo. Esse pode ser um indicador do cumprimento dos prazos ou um referencial numérico de produtividade.

Contudo, comprometimento se mostra a palavra-chave nesse processo. Hamel e Prahalad (1995) defendem que a busca pelo comprometimento de seus funcionários não consiste em um investimento financeiro que uma empresa faz em determinado projeto; mas sim um investimento intelectual que a empresa inteira faz em um determinado ponto de vista sobre o futuro, sendo evidenciado não apenas pelos níveis de investimento, mas pela aplicação da atenção e interesse da alta gerência.

\subsection{Kaplan e Norton (1996)}

Kaplan e Norton apresentaram pela primeira vez, em 1992, a metodologia que desenvolveram com base em estudo com 12 empresas, denominada Balanced Scorecard (BSC), que visava substituir os modelos tradicionais de avaliação de desempenho existentes nas organizações, os quais assentavam quase exclusivamente em indicadores financeiros, e desse modo se revelavam inadequados em contextos atuais de rápidas e constantes mudanças no ambiente competitivo das empresas. (KAPLAN; NORTON, 2002)

O BSC constitui-se em um conjunto de indicadores financeiros e não financeiros, estes últimos relacionados com a satisfação dos clientes, processos internos e a inovação e desenvolvimento; fatores estes considerados fundamentais para a competitividade das empresas. Com a utilização do BSC os gestores conseguem ter uma visão global do que se passa em suas organizações. (KAPLAN; NORTON, 2002)

Com o passar dos anos, os autores continuaram a desenvolver o BSC e esta metodologia, que começou 
a ser entendida como um sistema de avaliação de desempenho, foi evoluindo e transformou-se num sistema de gestão, que permite às organizações focalizarem-se na estratégia, através da construção de um mapa estratégico. (SOUZA; RODRIGUES, 2002)

Tal como acontece com o BSC, a construção de um mapa estratégico deve obedecer a uma lógica de cima para baixo. Kaplan e Norton (1996a) dividem a construção do mapa estratégico em quatro processos, conforme demonstra a figura:

\section{... Em torno do Balanced Scorecard}

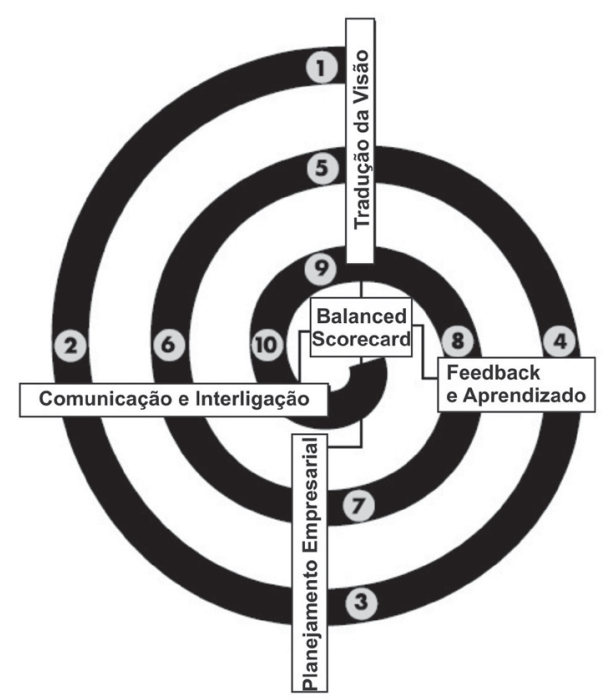

Figura 2: Em torno do Balanced Scorecard

Fonte: Adaptada de Kaplan e Norton (1996a, p. 79)

O primeiro processo consiste na "tradução da visão", o qual ajuda os gestores a construírem um consenso em torno da visão e da estratégia da organização. O segundo processo é denominado “comunicação e interligação" e permite aos gerentes comunicarem a sua estratégia para cima e para baixo na organização e vinculá-lo a objetivos departamentais $e$ individuais, assim garantindo que todos os níveis da organização compreendam a estratégia de longo prazo. O terceiro processo é a realização do "planejamento empresarial”, o qual permite à empresa integrar seus negócios e planos financeiros, em que os gerentes usam os ambiciosos objetivos fixados para as medidas BSC como base para a alocação de recursos e definição de prioridades. O quarto processo consiste no "feedback e aprendizado", através do qual as empresas desenvolvem a capacidade do aprendizado estratégico. (KAPLAN; NORTON, 1996a)

Com o Balanced Scorecard no centro de seus sistemas de gestão, a empresa pode monitorar os resultados de curto prazo a partir de três perspectivas: clientes, processos internos, aprendizado e crescimento, e avaliar a estratégia à luz do desempenho recente. Assim sendo, o BSC permite que as empresas modifiquem suas estratégias e reflitam a aprendizagem em tempo real. Ele fornece a capacidade de saber, em qualquer ponto da sua implementação, se a estratégia que eles formularam está de fato trabalhando, e se não, por quê (KAPLAN; NORTON, 1996a)

Contudo, o BSC, apresentado por Kaplan e Norton (1996a), alinha-se ao que neste trabalho denomina-se "pensamento estratégico", uma vez que visa envolver toda a organização com a estratégia organizacional, desde a base até o topo hierárquico. Principalmente o último processo do mapa estratégico, denominado "aprendizagem e feedback", demonstra a busca do desenvolvimento do pensamento estratégico, denominado "aprendizado estratégico", pois ele faz com que o BSC favoreça a aprendizagem sobre a organização, ao passo que permite aos gestores controlar e atuar na implementação da estratégia e, se necessário, fazer ajustamentos na própria estratégia.

Para Kaplan e Norton (1996b), o processo de feedback e aprendizagem é o mais inovador e mais importante de todo o processo de gestão do BSC, os autores afirmam: "[...] a capacidade para facilitar a aprendizagem organizacional [...] é o que diferencia o BSC, tornando-o inestimável para aqueles que desejam criar um sistema de gestão estratégica". (KAPLAN; NORTON, 1996b, p. 18)

Contudo, O BSC fixa os objetivos, mas assume que as pessoas empreenderão as ações necessárias para os atingi-los, define indicadores que os levem a atuar de acordo com a visão global da empresa, ele permite compreender muitas inter-relações, que poderão ajudar os gestores na tomada de decisões e na resolução de problemas. Ele tem uma orientação para o futuro, ao invés dos sistemas tradicionais que olhavam exclusivamente para o passado, dessa forma, alimentando o desenvolvimento do pensamento estratégico em toda a organização. 


\subsection{Liedtka (1998)}

Liedtka (1998) desenvolveu um modelo que define o pensamento estratégico como um caminho particular do pensamento, com características específicas e claramente identificáveis. A Figura 3 ilustra os cinco elementos do pensamento estratégico, propostos pela autora:

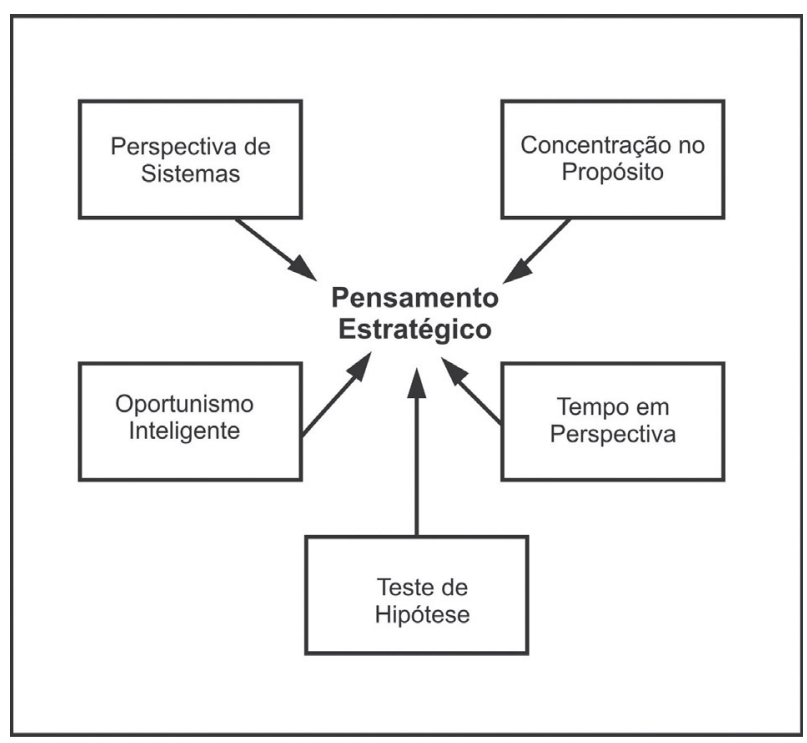

Figura 3: Elementos do Pensamento Estratégico

Fonte: Adaptada de Liedtka (1998, p. 122)

Além de apresentar os elementos, Liedtka (1998, p. 126) também apresenta uma associação de técnicas disponíveis para auxiliar no desenvolvimento desses elementos, conforme demonstra a Figura 4:

\begin{tabular}{|c|c|}
\hline Elementos do Pensamento estratégico & Relevantes Conceitos de Estratégia e Técnicas \\
\hline -Perspectiva de Sistemas & $\begin{array}{l}\text { - Mapeamento dos Stakeholder } \\
\text { - Análise do Sistema de Valores } \\
\text { - Conferências de Pesquisa do Futuro }\end{array}$ \\
\hline • Concentraçăo no Propósito & $\begin{array}{l}\text { •Histórias escritas } \\
\text { •Construçāo de cenários }\end{array}$ \\
\hline - Tempo em Perspectiva & $\begin{array}{l}\text {-Análise de lacunas } \\
\text {-Uso de analogias }\end{array}$ \\
\hline •Teste de Hipótese & $\begin{array}{l}\text { - O que se.... Se então } \\
\text {-Conhecido, Desconhecido, Presumido } \\
\text { - Questão de Alexandre }\end{array}$ \\
\hline -Oportunismo Inteligente & $\begin{array}{l}\text {-Partilhar e Comparar } \\
\text { - Técnicas de Simulaçäo }\end{array}$ \\
\hline
\end{tabular}

Figura 4: Repertório de construção

Fonte: Adaptada de Lietdka (1998, p. 126)

A "perspectiva de sistemas" consiste na visão de como o mundo funciona, incorporando um entendimento dos contextos interno e externo da organização. A "concentração no propósito" procura fazer com que o propósito estratégico dispense tempo necessário e suficiente para o alicerce do objetivo. O "tempo em perspectiva" trabalha com a história institucional e a criação do futuro. $\mathrm{O}$ "oportunismo inteligente" propõe que toda a organização deve praticar a intenção estratégia e permanecer fiel a ela. O "teste de hipóteses" visa à prática de métodos científicos que se concentram na habilidade de gerar boas hipóteses e de testá-las.

A combinação dos efeitos destes elementos é a criação da capacidade de pensar estrategicamente. Day (1994 apud LAWRENCE, 1999) apresenta três elementos fundamentais para as organizações que são capazes de usar estes recursos estrategicamente, são eles: 1) os elementos criam valor para o público interessado; 2) os elementos são de difícil imitação pelos concorrentes; 3 ) os elementos fazem com que a organização seja mais adaptável às mudanças.

Liedtka (1998) sugere que esses três elementos distintos, mas inter-relacionados, quando tomados em conjunto, podem levar a resultados positivos significativos nas organizações, desde que haja um planejamento estratégico, visto como um acompanhamento de apoio para incentivar e permitir a implementação dos frutos desse tipo de pensamento.

Desse modo, a autora defende o processo de planejamento como um catalisador de um diálogo de desenvolvimento aberto aos seus pontos de vista, que inclui os gestores de uma organização. Desse modo, a qualidade do diálogo depende da riqueza do repertório de cada indivíduo, bem como da sua capacidade de conversar com o outro. (LIEDTKA, 1998)

\subsection{Mintzberg (2004)}

Mintzberg, o precursor do termo "estratégia emergente", é um dos nomes que apontam as falhas do planejamento estratégico formal das organizações, defende também a necessidade do desenvolvimento do pensamento estratégico nas empresas.

Para Mintzberg (2004), decompor o processo de criação de estratégias, por exemplo, de forma que as metas sejam discutidas das $9 \mathrm{~h}$ às $10 \mathrm{~h} 30 \mathrm{~min}$, e que os pontos fortes e fracos sejam abordados das $10 \mathrm{~h} 30$ às $12 \mathrm{~h}$, pode abafar a discussão criativa.

De acordo com o autor, há alguma coisa errada na formalização aplicada a processos como a formação de estratégia, o que constitui uma das falácias do planejamento estratégico, que tange a natureza redu- 
cionista e analítica do planejamento; uma vez que a formalização é obtida por meio de decomposição, na qual um processo é reduzido a um procedimento, uma série de etapas, cada qual sendo especificada, o que torna o processo essencialmente analítico: a subdivisão do todo em suas partes. (MINTZBERG, 2004)

$\mathrm{O}$ analista tende a querer dar prosseguimento à etapa mais estruturada de avaliação das alternativas $e$, por isso, tende a dar pouca atenção a menos estruturada, mais difícil, mas geralmente mais importante etapa de diagnosticar o problema e gerar possíveis alternativas em primeiro lugar. Desse modo, o resultado tende a ser a solução conservadora do problema, muito inclinada para o status quo: os problemas são abordados como sempre foram concebidos, em função das alternativas já disponíveis. (MINTZBERG, 2004)

$\mathrm{O}$ processo de formação da estratégia, que envolve o pensamento estratégico, tem necessidades diferentes - de criatividade e de síntese - que depende do critério dos atores informados. Nesse sentido, Mintzberg (2004, p. 243) afirma que "[...] o trabalho de criar estratégia não pode ser programado da mesma forma que o de escavar carvão [...]", "[...] assim como a análise não é síntese, planejamento estratégico não é a formação de estratégia”. (MINTZBERG, 2004, p. 256)

$\mathrm{A}$ análise pode seguir e elaborar a síntese, decompondo e formalizando suas consequências. No entanto, a análise não pode substituir a síntese, pois nenhuma elaboração fará com que procedimentos formais possam prever descontinuidades, como informar gerentes desligados de suas operações ou criar novas estratégias em última análise. Com isso, a expressão "planejamento estratégico" demonstrou ser uma contradição. (MINTZBERG, 2004)

A síntese é vista por Mintzberg (2010) como a essência da gestão, a qual reúne tudo na forma de estratégias coerentes, organizações unificadas e sistemas integrados. Para o autor, é isso que torna a gestão tão difícil $-e$, ao mesmo tempo, tão interessante. No entanto, o autor esclarece que não consiste em os gerentes não precisarem de análise, uma vez que eles a necessitam como um insumo para a síntese.

Mintzberg (2010) também discorre sobre a construção da estratégia coletiva para o desenvolvimento de um pensamento estratégico, a qual exige que os gerentes adotem uma postura mais cooperativa e menos competitiva em relação aos seus pares. Obviamente, os funcionários também precisam ter bons motivos para acreditarem que o comportamento cooperativo será recompensado e que o avanço em suas carreiras depende tanto de assumirem a responsabilidade pelo progresso coletivo quanto de cumprirem suas próprias metas. Nesse sentido que um líder pode colocar em risco ou mesmo destruir as perspectivas do pensamento estratégico. No entanto, utilizar o potencial da "mente coletiva" é um dos desafios das organizações contemporâneas.

Segundo o autor, a disseminação do pensamento estratégico nas organizações envolve a geração de estratégia, sejam elas formuladas deliberadamente ou apenas formadas emergentemente, vista como uma "caixa preta" impenetrável para o planejamento, assim como para os planejadores, em torno da qual, e não dentro da qual, eles trabalham. (MINTZBERG, 2004)

\section{Conclusão}

No presente artigo, objetivou-se analisar uma nova forma de pensar as estratégias organizacionais, através de uma discussão teórica sobre o termo "pensamento estratégico" e o seu desenvolvimento nas organizações. Foi possível perceber que as implicações das visões sobre pensamento estratégico desafiam os processos tradicionais de planejamento, visto que faz repensar a capacidade de tomada de decisão estratégica.

Uma vez que as noções tradicionais de planejamento estratégico estão sob "ataque" por uma série de representantes da comunidade acadêmica e empresarial, com esta pesquisa foi possível constatar que é chegada a hora de buscar novas abordagens para melhorar as noções estratégicas fundamentais do que é e como funciona a estratégia.

No entanto, o processo de planejamento estratégico não perde sua importância na vida das organizações, uma vez que certo grau de formalização também é importante. Heracleous (1998), Lawrence (1999), Liedtka (1998) e Mintzberg (2004) defendem que o pensamento estratégico e o planejamento estratégico estão interligados e ambos são necessários para uma gestão estratégica, sendo que cada um por si só não é suficiente, eles precisam estar intimamente relacionados para trazerem benefícios à organização. 
Quanto ao pensar estratégico, também denota-se que ele está vinculado aos processos de mudança e aprendizado organizacional; e são as organizações que devem fornecer o contexto de apoio para seus membros desenvolverem tal capacidade, em todos os níveis organizacionais, formando uma "mente coletiva" capaz de pensar de forma sistêmica.

Ainda, vale destacar que apesar de estar ganhando crescente popularidade na literatura sobre planejamento organizacional e sobre estratégia, o pensamento estratégico não possui uma articulação clara quanto à sua natureza e suas implicações, parecem ainda faltar características precisas desse conceito. Ainda pouco se sabe sobre como a capacidade de pensar estrategicamente é realmente desenvolvida, e isso acaba por delimitar seu desenvolvimento por profissionais e pesquisadores, ou educadores.

Contudo, independentemente da clareza de sua definição e aplicação, com base no exposto, denota-se que o desenvolvimento do pensamento estratégico nas organizações é essencial para a sua sobrevivência nesses tempos de mudanças aceleradas e constantes. As características pragmáticas do planejamento estratégico parecem não ter mais espaço, e o desafio se apresenta em como as organizações podem desenvolver um planejamento estratégico que incentive o pensamento estratégico ao invés de miná-lo, utilizando da intuição $e$ da criatividade na formulação $e$ na formação de suas estratégias.

Desse modo, é válido chamar a atenção para o fato de que este artigo se constitui em um estudo inicial que busca compreender teoricamente o termo pensamento estratégico e seu desenvolvimento dentro das organizações, assim como seu caráter de complementariedade ao planejamento estratégico. Torna-se perceptível a demanda de novos estudos dada a complexidade que o tema envolve. A ideia é abrir caminhos para maiores discussões sobre o tema, e para o desenvolvimento de um modelo, que conte com um conjunto de ferramentas, que visem a fomentar o desenvolvimento do pensamento estratégico em funcionários de todos os níveis organizacionais, uma vez que ainda há grandes lacunas na compreensão de como o pensamento estratégico se desenvolve nos profissionais.

\section{ReferênCias Bibliográficas}

ACKOFF, R. L. Planejamento Empresarial. Rio de Janeiro: LTC - Livros técnicos e Científicos Editora, 1982. AMOROSO, R. Lidando com o pensamento estratégico. In: COSTA, B. K.; ALMEIDA, M. I. R. (Coord).

Estratégia: perspectivas e aplicações. São Paulo: Atlas, p. 31-52, 2002.

BELMIRO, J. Estratégias Emergentes. CAVALCANTI, M. (Org.). In: Gestão Estratégica de Negócios: evolução, cenários, diagnóstico e ação. São Paulo: Pioneira Thomson Learning, 2003. p. 289-319.

BOON, I. Developing strategic thinking as a core competency. Management Decision, v. 39, n.1, p. 63 71, 2001.

BOSSIDY, L., CHARAN, R. Desafio: fazer acontecer, a disciplina de execução nos negócios. 3. ed. Rio de Janeiro: Negócio, 2002.

BOSSIDY, L. A receita da execução. HSM Management, v. 4, n. 51, Ano 9, p. 40-44, jul.-ago. 2005.

FAIRHOM, M. R.; CARD, M. Perspectives of strategic thinking: from controlling chaos to embrancing it. Journal of Managemente \& Organization, v. 15, n. 1, p. 1730, mar. 2009.

GIL, Antônio Carlos. Pesquisa social. 4. ed. São Paulo: Atlas, 1994.

GRAETZ, F. Strategic thinking versus strategic planning: towards understanding the complementarities.

Management Decision, v. 31, n. 5, p. 456-462, 2002.

GOLDMAN, E.; CAHILL, T.; FILHO, R. P. Experiences that Develop the Ability to Think Strategically. Journal Of Healthcare Management, v. 54, n. 6, p. 403-417, nov.-dec. 2009.

GOLDMAN, E. F. Leadership practices that encourage strategic thinking. Journal of Strategy and

Management, v. 5, n. 1, p. 25-40, 2012.

HALL, R. H. Organizações: estrutura e processos. 3. ed. Rio de Janeiro: Prentice-Hall, 1984. 
HAMEL, G.; PRAHALAD, C. K. Competindo pelo

futuro: estratégias inovadoras para obter o controle do seu setor e criar os mercados de amanhã. 15. ed. Rio de Janeiro: Campus, 1995.

HERACLEOUS, L. Strategic thinking or strategic planning. Long Range Planning, v. 31, n. 3, p. 481487, 1998.

HREBINIAK, L. G. Fazendo a estratégia funcionar: o caminho para uma execução bem-sucedida. Rio Grande do Sul: Bookman, 2006.

KAPLAN, R. S.; NORTON, D. P. The Balanced Scorecard - Measures that Drive Performance, Harvard Business Review, p. 71-79, jan.-fev. 1992.

KAPLAN, R. S.; NORTON, D. P. Using the Balanced Scorecard as a strategic Management System, Harvard Business Review, p. 75-85, jan.-fev. 1996a.

KAPLAN, R. S.; NORTON, D. P. Strategic Learning \& Balanced Scorecard, Strategy \& Leadership, p. 18-24, set.-out. $1996 \mathrm{~b}$.

KICH, J. I. F; PEREIRA, M. F. Planejamento

Estratégico: os pressupostos básicos para uma implantação eficaz. São Paulo: Atlas, 2011.

LAKATOS, E. M.; MARCONI, M. A. Técnicas de pesquisa. São Paulo: Atlas, 2002.

LAWRENCE, E. Strategic Thinking: a discussion paper. Canada: Public Service Comission of Canada, 27, april. 1999 .

LIEDTKA, J. Strategic thinking; can it be taught?, Long Range Planning, v. 31, n. 1, p. 120-129, 1998.

MAXWEEL, J. W. Recognizing and Releasing Your Power of Strategic Thinking. weLEAD Online Magazine, Oct, 2010. Disponível em: <http://www.leadingtoday.org/ Onmag/2010\%20Archives/October\%2010/jm-october10. pdf $>$. Acesso em: $1^{\circ}$ jun. 2012.

MINTZBERG, H. Criando organizações eficazes:estruturas em cinco configurações. 2. ed. São Paulo: Atlas, 2003.

\section{MINTZBERG, H. Ascensão e queda do}

planejamento estratégico. Porto Alegre: Bookman, 2004.

MINTZBERG, H. Managing: desvendando o dia a dia da gestão. Porto Alegre: Bookman, 2010.

O'SHANNASSY, T. Strategic Thinking: a continuum of views and conceptualisation. RMIT Business, p. 24-30, 1999.

PRAHALAD, C. K.; FAHEY, L.; RANDALL, R. M. Estratégias para o crescimento: o papel das competências essenciais na corporação. In: FAHEY, L.; RANDALL, R. M. MBA: curso prático - estratégia. Rio de Janeiro: Campus, p.272-293, 1999.

SALAZAR, J. N. A. Pensamento Estratégico e Cenários. In: CAVALCANTI, M. (Org.); Gestão Estratégica de Negócios: evolução, cenários, diagnóstico e ação. São Paulo: Pioneira Thomson Learning, p. 123 -172, 2003.

SENGE, Peter. A quinta disciplina. São Paulo: Best Seller, 2006.

SOUZA, M. G. P.; RODRIGUES, L. M . P. L. O Balanced Scorecard: um instrumento de gestão estratégica para o século XXI. Porto: Editora Rei dos Livros, 2002.

TAVAKOLI, I.; LAWTON, J. Strategic thinking and knowledge management. Handbook of Business Strategy, v. 6, n. 1, p. 155-160, 2005.

WILSON, I. Strategic Planning Isn't Dead - It Changed. Long Range Planning, v. 27, n. 4, p. 12-24, 1994. 